\title{
Design, synthesis and thermal behaviour of a series of well-defined clickable and triggerable sulfonate polymers
}

Joanna Kolomanska, ${ }^{a}$ Priscilla Johnston, ${ }^{a}$ Alberto Gregori, b,a Isabel Fraga Dominguez, ${ }^{c, d, a}$ Hans-Joachim Egelhaaf ${ }^{e}+$, Sébastien Perrier, ${ }^{f, g}$ Agnès Rivaton, ${ }^{c, d}$ Christine Dagron-Lartigau ${ }^{b}$ and Paul D. Topham ${ }^{a *}$

\section{Abstract}

In the printing industry, the exploitation of triggerable materials that can have their surface properties altered on application of a post-deposition external stimulus has been crucial for the production of robust layers and patterns. To this end, herein, a series of clickable poly(R-alkyl $p$ styrene sulfonate) homopolymers, with systematically varied thermally-labile protecting groups, has been synthesised via reversible addition-fragmentation chain transfer (RAFT) polymerisation. The polymer range has been designed to offer varied post-deposition thermal treatment to switch them from hydrophobic to hydrophilic. Suitable RAFT conditions have been identified to produce welldefined homopolymers $\left(\Theta, M_{\mathrm{w}} / M_{\mathrm{n}}<1.11\right.$ in all cases) at high monomer conversions ( $>80 \%$ for all but one monomer) with controllable molar mass. Poly(p-styrene sulfonate) with an isobutyl protecting group has been shown to be the most readily thermolysed polymer that remains stable at room temperature, and was thus investigated further by incorporation into a diblock copolymer, P3HT- $b$-PiBSS, by click chemistry. The strategy for preparation of thermal modifiable block copolymers exploiting R-protected $p$-styrene sulfonates and azide-alkyne click chemistry presented herein allows the design of new, roll-to-roll processable materials for potential application in the printing industry, particularly organic electronics.

\section{Introduction}

Poly( $p$-styrene sulfonate), or poly( $p$-styrene sulfonic acid) (PSS), has been shown to be an extremely useful ion exchange material for a wide range of applications, such as water softening, ${ }^{1}$ medicine, ${ }^{2}$ biomaterials, ${ }^{3}$ and fuel cells. ${ }^{4}$ Most notably, perhaps, is the exploitation of PSS as a dopant for poly(3,4-ethylenedioxythiophene) (PEDOT) in organic electronic devices. ${ }^{5-7}$ Negatively charged PSS forms a complex with positively charged ( $p$-type) PEDOT to produce hole conducting 'buffer' layers in organic photovoltaics (OPVs), hole injection layers in organic light emitting diodes (OLEDs) or as a possible electrode replacement for indium tin oxide (ITO). ${ }^{8,9}$ However, PSS is a polar polymer and cannot be readily processed from organic solvents that are used typically for the deposition of the more apolar conducting materials, such as polythiophenes, ${ }^{10,11}$ polycarbazoles ${ }^{12,13}$ and fullerene derivatives. ${ }^{11,14}$ Consequently, this can limit the applicability of PSS in solution-processable technologies, despite its clear relevance. Additionally, the preparation of non-polar/polar hybrid materials (such as amphiphilic block copolymers ${ }^{15-17}$ ) can be difficult owing to the contradictory solubilities of the disparate building blocks.

Typically, PSS is produced by the sulfonation of polystyrene using concentrated sulfuric acid, ${ }^{18,19}$ acetyl sulfate ${ }^{20,21}$ or sulfur trioxide. ${ }^{22,23}$ However, problems over control of the sulfonation level have led to the development of alternative methods. Accordingly, controlled polymerisation methods, namely nitroxide-mediated polymerisation (NMP), ${ }^{17,24,25}$ atomic transfer radical polymerisation (ATRP), ${ }^{26-28}$ and reversible addition-fragmentation chain transfer (RAFT) polymerisation, ${ }^{29-31}$ have been exploited to obtain sodium poly( $p$-styrene sulfonate). Another 
strategy presents ATRP of poly(ethyl $p$-styrene sulfonate) followed by the chemical deprotection of the ethyl ester functionality using sodium azide ${ }^{32}$ or sodium hydroxide, ${ }^{33}$ both in DMF/water cosolvent systems.

As aforementioned, and discussed across the literature, the processing of PSS from most organic solvents requires the introduction of a protecting group to remove the ionic character of the sulfonic acid group. Deprotection of the sulfonate group is therefore essential in order to restore the ion exchange properties of PSS. ${ }^{32-37}$ Similarly, a related strategy has been employed to process conjugated polymers for use in OPV. Incorporation of alkyl side chains into the monomer (and hence pendent along the final macromolecular chain) is a widely used approach for improvement of solubility of extensive aromatic systems. ${ }^{38,39}$ Unfortunately, however, such alkyl chains have been shown to promote degradation. ${ }^{40,41}$ Hence, cleavage of the alkyl chains directly after processing the polymers is recommended to overcome this problem. Several investigations concerning chemicallyand thermally-assisted removal have been undertaken. ${ }^{42-45}$ Chemical routes profit from high side chain cleavage efficiency. However, in roll-to-roll technology, widely used in the application of coatings (particularly pertinent for the industrial production of many organic electronic devices), chemical modification is undesirable as a processing technique because of the cost, complications of washing, chemical waste and possible damage to other materials in the system. The use of thermally-assisted deprotection of functional groups significantly diminishes these issues.

Nonetheless, caution must be exercised with this approach, as excessive temperatures lead to lower OPV performances and damage to the flexible plastic substrates. ${ }^{46,47}$ Indeed, acid-catalysed cleavage can allow a decrease in processing temperature, ${ }^{48}$ however, the removal of the catalyst following deprotection could be necessary for certain applications (particularly organic electronics, where trace amounts of contaminants can severely impact device performance). To this end, use of a thermolabile neopentyl group for the preparation of a PSS precursor has been previously reported. ${ }^{36}$, 37,49

Most pertinently, our group has synthesised poly(3-hexylthiophene)- $b$-poly(neopentyl styrene sulfonate) (P3HT-b-PNSS) as a potential interlayer for adhesion improvement in OPVs. ${ }^{49}$ Conditions required for neopentyl group removal both from PNSS homopolymer and P3HT- $b$-PNSS copolymer have been studied. The results showed that the presence of P3HT leads to longer deprotection times of the PNSS block, limiting the application of this material in OPVs. As aforementioned, prolonged high temperature treatment should be avoided during OPV processing as it can cause degradation of cells and a loss of performance.

In the quest for more suitable material, herein, we have selected and synthesised a systematic range of styrene sulfonate monomers bearing different linear and branched aliphatic protecting groups, namely: n-propyl (2), isopropyl (3), $n$-butyl (4), isobutyl (5), n-pentyl (6) and neopentyl (7) (see Figure 1). ${ }^{34,50-53}$ These monomers have been polymerised via RAFT ${ }^{54-56}$ using an azide-functionalised CTA, which to the best of our knowledge, is the first report of not only radical, but also controlled radical polymerisation of $\mathbf{2 , 4} \mathbf{5}$ and $\mathbf{6}$. It should be noted that photochemically-initiated radical polymerisation of $3^{52}$ and NMP ${ }^{57-59}$, ATRP $^{34-37}$ and RAFT ${ }^{60}$ of $\mathbf{7}$ have been reported. In this submission, the thermal lability of the various protecting groups is systematically assessed using thermogravimetric analysis (TGA) to identify a well-defined, readily processable poly( $p$-styrene sulfonate) precursor. 
Appropriate synthetic conditions have been identified to successfully polymerise all of these monomers with relatively high conversion ( $>80 \%$, for all but the isobutyl derivative) and low molar mass dispersity $(\theta<1.11)$. The thermal modification of the resultant polymers is shown to be more facile for branched protecting groups rather than linear ones. Moreover, owing to the azidefunctionalised CTA used in the RAFT polymerisations, all the synthesised polymers bear a terminal azide group which, as demonstrated herein, can be exploited for the construction of diblock copolymers using azide-alkyne click chemistry.

\section{Experimental}

\section{Materials}

Methanol (MeOH), dichloromethane (DCM), hexane were purchased from Fisher Scientific and used as supplied. 1,4-Diazabicyclo[2.2.2] ]octane (DABCO, $98 \%$ ), sodium chloride (99\%), anhydrous magnesium sulfate $(99.5 \%)$, isobutanol ( $\geq 99 \%$ ) were purchased from Alfa Aesar and used as received. Propan-2-ol (99.5\%), butan-1-ol ( $\geq 99 \%)$, pentan-1-ol ( $\geq 99 \%$ ) and anhydrous tetrahydrofuran (THF) ( $\geq 99.9 \%$ ) were purchased from Sigma Aldrich and used as received without further purification. Chloroform-d (99.8 \% At + $0.05 \%$ TMS, Goss Scientific) and 2,2'-

Azobis(isobutyronitrile) (AIBN, TCl), propan-1-ol ( $\geq 99 \%$, Lancaster Synthesis) were used as supplied. 2-azidoethyl 2-(dodecylthiocarbonothioylthio)-2-methylpropionate (CTA- $\mathrm{N}_{3}$, Figure S1, ESI) ${ }^{61}$ and P3HT-ethynyl $\left(D_{\mathrm{p}}=50 \text {, estimated from }{ }^{1} \mathrm{H} \mathrm{NMR}\right)^{49}, p$-styrene sulfonyl chloride $(\mathbf{1})^{62}$ were synthesised according to the relevant literature procedures. A poly(styrene sulfonic acid) solution $\left(M_{\mathrm{n}} 75000\right.$ $\mathrm{g} / \mathrm{mol}, 18 \mathrm{wt} \%$ in $\mathrm{H}_{2} \mathrm{O}$ ) was obtained from Sigma Aldrich and was lyophilised prior to use.

\section{Methods}

\section{Synthesis of monomers}

$p$-Styrene sulfonyl chloride $(1,8.0 \mathrm{~g}, 39 \mathrm{mmol})$ was added dropwise at $0{ }^{\circ} \mathrm{C}$ to a stirring solution of DABCO (1.2 eq.) and ROH (1.5 eq.) in DCM (100 ml). The reaction mixture was allowed to warm up to room temperature and was then stirred overnight. After which, $100 \mathrm{ml}$ water was added and the layers were separated. The organic layer was washed with water $(3 \times 150 \mathrm{ml})$ and brine $(200 \mathrm{ml})$. After drying over magnesium sulfate, the solvent was removed and hexane $(250 \mathrm{ml})$ was added to the residues. The mixture was heated to $65^{\circ} \mathrm{C}$, stirred for 15 minutes and the solution was separated from the solids by decantation. Hexane was removed under vacuum to afford the product as a yellow oil. ${ }^{1} \mathrm{H}$ and ${ }^{13} \mathrm{C}$ NMR spectra for all monomers are provided in the ESI (Figures S2 - S7).

$n$-Propyl $p$-styrene sulfonate (2)

The general procedure was followed to give $2(32 \%) .{ }^{1} \mathrm{H} \mathrm{NMR}$ in $\mathrm{CDCl}_{3}(\delta, \mathrm{ppm}): 0.89$ (t, 3H, $J=9.0$ $\mathrm{Hz}$ ), 1.67 (sextet, $2 \mathrm{H}, J=8.1 \mathrm{~Hz}$ ), $4.00(\mathrm{t}, 2 \mathrm{H}, J=7.8 \mathrm{~Hz}$ ), $5.45(\mathrm{~d}, 1 \mathrm{H}, J=13.2 \mathrm{~Hz}), 5.90(\mathrm{~d}, 1 \mathrm{H}, J=21.0$ $\mathrm{Hz}) 6.75(\mathrm{dd}, 1 \mathrm{H}, J=21.1,13.0 \mathrm{~Hz}), 7.54(\mathrm{~d}, 2 \mathrm{H}, J=9.9 \mathrm{~Hz}), 7.85(\mathrm{~d}, 2 \mathrm{H}, J=10.2 \mathrm{~Hz}) .{ }^{13} \mathrm{C} N M R$ in $\mathrm{CDCl}_{3}(\delta, \mathrm{ppm}):$ 9.9, 22.4, 72.3, 118.0, 126.8, 128.3, 135.2, 142.7 .

Isopropyl $p$-styrene sulfonate (3) 
The general procedure was followed to give $3(41 \%) .{ }^{1} \mathrm{H}$ NMR in $\mathrm{CDCl}_{3}(\delta, \mathrm{ppm}): 1.26(\mathrm{~d}, 6 \mathrm{H}, J=$ $6.3 \mathrm{~Hz}$ ), 4.73 (septet, $1 \mathrm{H}, J=6.3 \mathrm{~Hz}$ ), $5.44(\mathrm{~d}, 1 \mathrm{H}, J=10.8 \mathrm{~Hz}$ ), $5.89(\mathrm{~d}, 1 \mathrm{H}, J=17.7 \mathrm{~Hz}$ ), $6.74(\mathrm{dd}, 1 \mathrm{H}$, $J=17.4,12.0 \mathrm{~Hz}$ ), $7.53(\mathrm{~d}, 2 \mathrm{H}, J=8.4 \mathrm{~Hz}), 7.84(\mathrm{~d}, 2 \mathrm{H}, J=8.4 \mathrm{~Hz}) .{ }^{13} \mathrm{C} \mathrm{NMR}$ in $\mathrm{CDCl}_{3}(\delta, \mathrm{ppm}): 22.7$, $77.4,117.9,126.8,127.9,135.2,136.2,142.6$.

$n$-Butyl p-styrene sulfonate (4)

The general procedure was followed to give $4(22 \%) .{ }^{1} \mathrm{H} \mathrm{NMR}$ in $\mathrm{CDCl}_{3}(\delta, \mathrm{ppm}): 0.859$ (t, 3H, $J=9.0$ $\mathrm{Hz}), 1.34(\mathrm{~m}, 2 \mathrm{H}), 1.60(\mathrm{~m}, 2 \mathrm{H}), 4.04(\mathrm{t}, 2 \mathrm{H}, J=7.8 \mathrm{~Hz}), 5.46(\mathrm{~d}, 1 \mathrm{H}, J=12.0 \mathrm{~Hz}), 5.90(\mathrm{~d}, 1 \mathrm{H}, J=21.0$

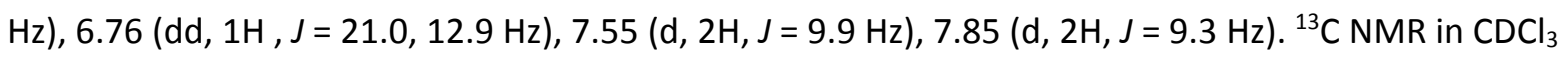
$(\delta, \mathrm{ppm}): 13.4,18.6,30.8,70.6,118.0,126.8,128.2,135.2,142.8$.

Isobutyl $p$-styrene sulfonate (5)

The general procedure was followed to give $5(25 \%) .{ }^{1} \mathrm{H} N M R$ in $\mathrm{CDCl}_{3}(\delta, \mathrm{ppm}): 0.87(\mathrm{~d}, 6 \mathrm{H}, J=8.1$ $\mathrm{Hz}$ ), 1.93 (septet, $1 \mathrm{H}, J=8.1 \mathrm{~Hz}$ ), $3.79(\mathrm{~d}, 2 \mathrm{H}, J=7.8 \mathrm{~Hz}), 5.44(\mathrm{~d}, 1 \mathrm{H}, J=12.9 \mathrm{~Hz}), 5.90(\mathrm{~d}, 1 \mathrm{H}, J=$ $21.0 \mathrm{~Hz}), 6.74(\mathrm{dd}, 1 \mathrm{H}, J=21.0,12.0 \mathrm{~Hz}), 7.53(\mathrm{~d}, 2 \mathrm{H}, J=9.9 \mathrm{~Hz}), 7.83(\mathrm{~d}, 2 \mathrm{H}, J=10.2 \mathrm{~Hz}) .{ }^{13} \mathrm{C} \mathrm{NMR}$ in $\mathrm{CDCl}_{3}(\delta, \mathrm{ppm}): 18.6,28.0,76.5,118.0,126.7,128.3,135.2,142.8$.

$n$-Pentyl $p$-styrene sulfonate (6)

The general procedure was followed to give $6(30 \%) .{ }^{1} \mathrm{H} \mathrm{NMR} \mathrm{in} \mathrm{CDCl}_{3}(\delta, \mathrm{ppm}): 0.83(\mathrm{~m}, 3 \mathrm{H}), 1.27$ $(\mathrm{m}, 4 \mathrm{H}), 1.64(\mathrm{~m}, 2 \mathrm{H}), 4.03(\mathrm{t}, 2 \mathrm{H}, \mathrm{J}=7.8), 5.45(\mathrm{~d}, 1 \mathrm{H}, J=12.9 \mathrm{~Hz}), 5.90(\mathrm{~d}, 1 \mathrm{H}, J=21 \mathrm{~Hz}), 6.75(\mathrm{dd}$, $1 \mathrm{H}, J=21.0,15 \mathrm{~Hz}), 7.54(\mathrm{~d}, 2 \mathrm{H}, J=10.2 \mathrm{~Hz}), 7.85(\mathrm{~d}, 2 \mathrm{H}, J=9.9 \mathrm{~Hz}) .{ }^{13} \mathrm{C} \mathrm{NMR}$ in $\mathrm{CDCl}_{3}(\delta, \mathrm{ppm}): 13.9$, $22.0,27.4,28.5,70.9,118.1,126.8,128.2,135.2,142.8$.

Neopentyl $p$-styrene sulfonate (7) synthesis

NSS was prepared according to the literature procedure. ${ }^{53}$

\section{RAFT polymerisation of monomers}

General procedure for the synthesis of R-protected polymers (8-13)

Polymerisation reactions were performed using Carousel 12 Plus, a set up for parallel syntheses from R. B. Radley Co. Ltd. Monomer (2-7) (1.0 g), AIBN (0.01 eq.) and RAFT agent (CTA- $\mathrm{N}_{3}, 0.05$ eq.) were added to the reaction tubes. The system was degassed three times via vacuum and nitrogen cycles, before anhydrous THF $(2.7 \mathrm{ml})$ was added and the resulting mixture was then degassed again. To start the polymerisation, the system was heated to $60{ }^{\circ} \mathrm{C}$ and then allowed to proceed for approximately 120 hours. Reaction progress was monitored by collecting samples periodically and analysing by ${ }^{1} \mathrm{H}$ NMR and GPC. The reaction was stopped after 120 hours by cooling down the system to room temperature. For purification, the reaction mixture was diluted with THF $(2 \mathrm{ml})$ and reprecipitated into methanol $(200 \mathrm{ml})$. The polymer was filtered off and dried under vacuum overnight. Yields ranged from 58 to $90 \%$ depending on the monomer used. It is important to note that the isopropyl monomer was also polymerised using 0.04 eq. of CTA (with identical conditions to above) for 72 hours to obtain polymer with similar $M_{\mathrm{n}}$ to all other polymers. This shorter reaction time was essential to avoid removal of the isopropyl group during polymerisation, which was observed after 120 hours. ${ }^{1} \mathrm{H}$ NMR of polymers are provided in the ESI (Figures S8 - S13). 
Poly(n-propyl $p$-styrene sulfonate) (8):

$M_{\mathrm{n}}=3300 \mathrm{~g} / \mathrm{mol}, \oplus=1.09 .{ }^{1} \mathrm{H} \mathrm{NMR}$ in $\mathrm{CDCl}_{3}(\delta, \mathrm{ppm}): 0.90(\mathrm{br}, 3 \mathrm{H}), 1.22\left(\mathrm{br}, 20 \mathrm{H}\right.$ from CTA- $\mathrm{N}_{3}$ moiety), $1.71(\mathrm{br}, 5 \mathrm{H}), 4.05(\mathrm{br}, 2 \mathrm{H}), 6.70(\mathrm{br}, 2 \mathrm{H}), 7.69(\mathrm{br}, 2 \mathrm{H})$.

Poly(isopropyl $p$-styrene sulfonate) (9):

$M_{\mathrm{n}}=3800 \mathrm{~g} / \mathrm{mol}, \Theta=1.08 .{ }^{1} \mathrm{H} \mathrm{NMR}$ in $\mathrm{CDCl}_{3}(\delta, \mathrm{ppm}): 1.30\left(\mathrm{br}, 6 \mathrm{H}\right.$ from iPSS and 20H from CTA- $\mathrm{N}_{3}$ moiety), $1.62(\mathrm{br}, 3 \mathrm{H}), 4.83(\mathrm{br}, 1 \mathrm{H}), 6.69(\mathrm{br}, 2 \mathrm{H}), 7.72(\mathrm{br}, 2 \mathrm{H})$.

Poly( $n$-butyl $p$-styrene sulfonate) (10):

$M_{\mathrm{n}}=3800 \mathrm{~g} / \mathrm{mol}, \oplus=1.08 .{ }^{1} \mathrm{H} \mathrm{NMR}$ in $\mathrm{CDCl}_{3}(\delta, \mathrm{ppm}): 0.86(\mathrm{br}, 3 \mathrm{H}), 1.23(\mathrm{br}, 2 \mathrm{H}$ from CTA-N 3 moiety), 1.37 (br, 3H), $1.68(\mathrm{br}, 4 \mathrm{H}), 4.09$ (br, 2H), $6.71(\mathrm{br}, 2 \mathrm{H}), 7.70(\mathrm{br}, 2 \mathrm{H})$.

Poly(isobutyl $p$-styrene sulfonate) (11):

$M_{\mathrm{n}}=3000 \mathrm{~g} / \mathrm{mol}, \oplus=1.08 .{ }^{1} \mathrm{H} \mathrm{NMR}$ in $\mathrm{CDCl}_{3}(\delta, \mathrm{ppm}): 0.92(\mathrm{br}, 6 \mathrm{H}), 1.24\left(\mathrm{br}, 20 \mathrm{H}\right.$ from CTA- $\mathrm{N}_{3}$ moiety), $1.64(\mathrm{br}, 3 \mathrm{H}), 2.00(\mathrm{br}, 1 \mathrm{H}), 3.87(\mathrm{br}, 2 \mathrm{H}), 6.72(\mathrm{br}, 2 \mathrm{H}), 7.74(\mathrm{br}, 2 \mathrm{H})$.

Poly(n-pentyl $p$-styrene sulfonate) (12):

$M_{\mathrm{n}}=3900 \mathrm{~g} / \mathrm{mol}, \Theta=1.08 .{ }^{1} \mathrm{H} \mathrm{NMR}$ in $\mathrm{CDCl}_{3}(\delta, \mathrm{ppm}): 0.84(\mathrm{br}, 3 \mathrm{H}), 1.17(\mathrm{br}, 20 \mathrm{H}$ from CTA-N 3 moiety), $1.20(\mathrm{br}, 5 \mathrm{H}), 1.67(\mathrm{br}, 4 \mathrm{H}), 4.05(\mathrm{br}, 2 \mathrm{H}), 6.68(\mathrm{br}, 2 \mathrm{H}), 7.67(\mathrm{br}, 2 \mathrm{H})$.

Poly(neopentyl $p$-styrene sulfonate) (13):

$M_{\mathrm{n}}=3500 \mathrm{~g} / \mathrm{mol}, \nexists=1.11 .{ }^{1} \mathrm{H} \mathrm{NMR}$ in $\mathrm{CDCl}_{3}(\delta, \mathrm{ppm}): 0.90(\mathrm{br}, 9 \mathrm{H}), 1.23\left(\mathrm{br}, 20 \mathrm{H}\right.$ from CTA- $\mathrm{N}_{3}$ moiety), $1.62(\mathrm{br}, 2 \mathrm{H}), 1.82(\mathrm{br}, 1 \mathrm{H}), 3.75(\mathrm{br}, 2 \mathrm{H}), 6.71(\mathrm{br}, 2 \mathrm{H}), 7.71(\mathrm{br}, 2 \mathrm{H})$.

Synthesis of poly(isobutyl p-styrene sulfonate) macroCTA (PiBSS) for the preparation of poly(3hexylthiophene)-block-poly(isobutyl p-styrene sulfonate) (P3HT-b-PiBSS)

PiBSS- $\mathrm{N}_{3}$ was prepared according to the general procedure for the synthesis of R-protected polymers (8-13) with some modifications. In order to shorten the reaction time and limit possible side reactions, the synthesis was performed using more concentrated reaction mixture $(1 \mathrm{~g}$ of iBSS $/ 1 \mathrm{ml}$ of THF) than that used for synthesis of the aforementioned polymer series (8-13), and the reaction was stopped after $72 \mathrm{~h} . M_{\mathrm{n}}=3900 \mathrm{~g} / \mathrm{mol} ; \emptyset=1.16 ; D_{\mathrm{p}}=14$, estimated from GPC against polystyrene standards. This homopolymer was also used in the TGA experiment using PSS-doped PiBSS.

\section{Synthesis of poly(3-hexylthiophene)-block-poly(isobutyl p-styrene sulfonate) (P3HT-b-PiBSS)}

P3HT-ethynyl, ( $D_{\mathrm{p}}=50,150 \mathrm{mg}, 11.9 \mu \mathrm{mol}, 1$ eq.), PiBSS- $\mathrm{N}_{3}\left(D_{\mathrm{p}}=14,190 \mathrm{mg}, 47.6 \mu \mathrm{mol}, 4\right.$ eq.), Cul (9.1 mg, $47.6 \mu \mathrm{mol}, 4$ eq.), DIPEA (diisopropylethylamine, $1 \mathrm{ml}$ pre-degassed with bubbling $\mathrm{N}_{2}$ for 0.5 h) and THF (20 ml) were charged to a $50 \mathrm{ml}$ round-bottomed flask, evacuated for 10 minutes and backfilled with nitrogen ( 3 cycles). The flask was then kept at $50{ }^{\circ} \mathrm{C}$ for 48 hours, following which, the solution was passed through a neutral alumina column to remove the copper catalyst. After concentrating the solution in vacuo, the product was recovered by precipitation in methanol, dried under reduced pressure, and then subjected to soxhlet purification with methanol and acetone, 
respectively. The product was finally extracted with chloroform, concentrated under reduced pressure and dried under vacuum overnight to yield the block copolymer.

Recovery: $76.8 \% ; M_{\mathrm{n}}=19300 \mathrm{~g} / \mathrm{mol} ; \exists=1.27$; Selected IR bands: $2961 \mathrm{~m}$ (sh.), $2926 \mathrm{~s}, 2861 \mathrm{~s}, 1735$ w, 1597 w, 1578 w, 1506 w, 1455 m, 1357 m, 1274 w, 1176 s, 1100 w, 972 m, 938 m, 822 s, 718 w, 662 w. ${ }^{1} \mathrm{H}$ NMR: See Figure S22, ESI for spectrum and assignment.

\section{TGA Study of polymers}

3-4 mg sample of polymer (8-13) was placed in a TGA pan and measurements were performed in two modes; a temperature sweep from 25 to $500{ }^{\circ} \mathrm{C}$ (at a rate of $10{ }^{\circ} \mathrm{C} / \mathrm{min}$ ) [Figure $4(\mathrm{a})$ ] and an isothermal profile $\left(150^{\circ} \mathrm{C}\right)$ for 120 minutes [Figure $4(\mathrm{~b})$ ]. Samples after the isothermal measurements were further analysed by FTIR ATR (Figure S14, ESI).

\section{TGA Study of PSS-catalysed thermolysis of PiBSS}

PiBSS and PSS were ground together using a mortar and pestle to produce homogenous PiBSS samples containing 11.9, 26.2, 41.1 and $52.2 \%$ (w/w) PSS. Approximately 5-10 mg of each mixed sample was then subjected to isothermal thermogravimetric analysis $\left(150^{\circ} \mathrm{C}, 2 \mathrm{~h}\right)$.

\section{Characterisation}

${ }^{1} \mathrm{H}\left(300 \mathrm{MHz}\right.$ ) and DEPT ${ }^{13} \mathrm{C}$ NMR (75 MHz) Spectroscopy (positive peaks correspond to $-\mathrm{CH}_{3}$ and $-\mathrm{CH}-$ groups and negative peaks to - $\mathrm{CH}_{2}$ - groups) was carried out on a Bruker Avance Spectrometer, where R-protected monomers and polymers were dissolved in $\mathrm{CDCl}_{3}$ and PSS-doped PiBSS in $\mathrm{d}_{6}{ }^{-}$ DMSO. ${ }^{1} \mathrm{H}$ NMR Spectroscopy was also used to calculate monomer conversion during RAFT polymerisation. Relative number-average molecular weight $\left(M_{n}\right)$ and dispersity $\left(M_{w} / M_{n}, \oslash\right)$ were measured by Gel Permeation Chromatography (GPC) (flow rate $1 \mathrm{ml} / \mathrm{min}, 40^{\circ} \mathrm{C}$ ) using a Varian GPC spectrometer comprising three PL gel $5 \mu \mathrm{m} 300 \times 7.5 \mathrm{~mm}$ mixed-C columns and a degassed THF eluent system containing triethylamine $(2 \% \mathrm{v} / \mathrm{v})$ and $\mathrm{BHT}(0.05 \% \mathrm{w} / \mathrm{v})$. The samples were calibrated with narrow polystyrene standards $\left(M_{\mathrm{p}}\right.$ range $=162$ to $6035000 \mathrm{~g} / \mathrm{mol}$ ) and analysed using PL Cirrus software (version 2.0) supplied by Agilent Technologies. Fourier transform infrared (FTIR) spectra of all the samples were obtained using attenuated total reflectance (ATR) on a Thermo Nicolet 380 FTIR spectrophotometer over the range $4000-500 \mathrm{~cm}^{-1}$ for 8 scans with a resolution of $4 \mathrm{~cm}^{-1}$. Thermogravimetric analysis (TGA) was obtained using a Pyris 1 Thermogravimetric analyser under nitrogen atmosphere (flow rate $25 \mathrm{ml} / \mathrm{min}$ ). The contact angles of water on PiBSS- $\mathrm{N}_{3}$ and PiBSS- $b$ P3HT substrates were measured using a Krüss Drop Shape Analyser (DSA 10, Krüss GmbH, Hamburg, Germany). Contact angles were obtained by releasing a drop of deionised $\mathrm{H}_{2} \mathrm{O}(3 \mu \mathrm{L})$ onto the sample surface, and the values reported herein represent an average of 3 measurements taken at 3 locations across the substrate surface.

\section{Results and discussion}

Recently, the polymerisation of neopentyl $p$-styrene sulfonate has been studied in depth in our laboratory. ${ }^{63}$ Herein to improve the processability of the final polymer, broader research on a series of R-protected $p$-styrene sulfonates is presented, comprising synthesis and RAFT polymerisation of 
systematically varied monomers (2-7). R-protected $p$-styrene sulfonate monomers (2-7) were synthesised in a two-step process from sodium $p$-styrene sulfonate as presented in Scheme 1. Each monomer in the series was then polymerised via RAFT using AIBN and CTA-N $\mathrm{N}_{3}$ in THF at $60^{\circ} \mathrm{C}$.

Introduction of terminal azide functionality into the chain transfer agent enables the polymers to be further used as building blocks in the production of more complex materials (such as block copolymers) via click chemistry. ${ }^{64-66}$ Of note, caution should be taken when employing azidefunctionalised moieties in thermally-driven polymerisations due to unwanted reaction with electronpoor olefinic monomers, such as acrylamides and (meth)acrylates. ${ }^{67}$ Styrenic monomers, on the other hand, have been shown not be particularly susceptible to this phenomenon. ${ }^{67}$ Polymerisations were performed in THF $(37 \% \mathrm{w} / \mathrm{v})$ at $60^{\circ} \mathrm{C}$ for $120 \mathrm{~h}$. To follow the progress of each reaction, samples were taken after $2,8,24,32,48,56,72,120 \mathrm{~h}$ and analysed by GPC and ${ }^{1} \mathrm{H}$ NMR spectroscopy. High monomer conversion after $120 \mathrm{~h}(>80 \%)$ was observed in all reactions, except the polymerisation of isobutyl $p$-styrene sulfonate (5), where an acceptable $69 \%$ was reached. In most of the reactions (3-7), a plateau was observed after $72 \mathrm{~h}$ (Figure 2a), showing no further significant polymerisation was occurring after this point. It is noteworthy that partial removal of the isopropyl protecting group was observed during polymerisation after $120 \mathrm{~h}$ at this temperature. To obtain poly(isopropyl $p$-styrene sulfonate) of a similar molar mass to the remaining polymers in the series, polymerisation of $\mathbf{3}$ was repeated using 0.04 eq. CTA (target $D_{\mathrm{p}}=25$ ) and stopped after $72 \mathrm{~h}$ to avoid premature thermolysis. Indeed, GPC analyses show that the attained molar masses for all polymers were within 3000 to $3900 \mathrm{~g} / \mathrm{mol}$ (Table 1). All products displayed unimodal GPC traces (Figure $2 \mathrm{~b}$ ) with low molar mass dispersities $(\Theta \leq 1.11$, Table 1$)$. Interestingly, although AIBN has a half-life of approximately 20 hours at $60^{\circ} \mathrm{C}$, propagation continued up to approximately 72 hours in most cases and is attributed to thermally-induced self-polymerisation of styrenic monomers. ${ }^{68}$

To demonstrate the control of molar mass in RAFT polymerisations, the evolution of the molar mass and dispersity is presented in Figure 3. A linear increase of molecular mass versus conversion for all polymerised monomers was observed, and the dispersity remained low throughout the reactions ( $\leq$ 1.12 in all cases). Semi-logarithmic first order plots and corresponding GPC traces throughout each polymerisation have been included in the ESI (Figures S15 a-f and Figure S16).

\section{Thermolysis}

TGA has been employed to examine the thermal modification profiles of our polymers (8-13) to produce poly( $p$-styrene sulfonate), PSS. Measurements were performed in two modes; a temperature sweep from 25 to $500{ }^{\circ} \mathrm{C}$ (at a rate of $10{ }^{\circ} \mathrm{C} / \mathrm{min}$ ) [Figure $4(\mathrm{a})$ ] and an isothermal profile $\left(150^{\circ} \mathrm{C}\right.$ ) for 120 minutes [Figure $4(\mathrm{~b})$ ]. The data clearly show that the weight loss of the branched polymers, occurring at approximately $150{ }^{\circ} \mathrm{C}(9)$ and $200^{\circ} \mathrm{C}(\mathbf{1 1}, \mathbf{1 3})$ in the temperature sweep experiment [Figure 4(a)], occurs more readily than the weight loss in the linear counterparts $(\mathbf{8}, \mathbf{1 0}$, 12), observed at approximately $230^{\circ} \mathrm{C}$. For the isothermal $\left(150^{\circ} \mathrm{C}\right)$ treatment, the significant weight loss is observed after $7 \mathrm{~min}$ for $\mathbf{9}, 30 \mathrm{~min}$ for $\mathbf{1 1}$ and $80 \mathrm{~min}$ for 13, whereas for the linear polymers only a minor decrease of weight is observed after 120 minutes. The observed weight loss is attributed to removal of the protecting group from the sample. However, it is noteworthy that the initial obtained weight loss percentage observed in Figure 4(b) differs from the theoretically calculated values in the case of isobutyl and neopentyl derivatives; $11 \%$ and $12 \%$ compared to $21 \%$ and $\mathbf{2 5 \%}$ theoretical values for $\mathbf{1 1}$ and $\mathbf{1 3}$ (including release of nitrogen from the azide group), ${ }^{69,70}$ 
respectively. This difference is attributed to a Friedel-Crafts side reaction which results in attachment of some of the alkyl protecting groups to the aromatic ring of the polymer at the meta position. Observation of this phenomenon has already been described for poly(neopentyl $p$-styrene sulfonate). ${ }^{36,37}$ Interestingly, the observed weight loss closely matches the theoretically calculated values for the polymer with isopropyl protecting group (9). Isothermal TGA [Figure 4(b)] shows the differences in the time required for protecting group removal, indicating the ease of deprotection in the following order (starting with the most readily deprotected): isopropyl (9)> isobutyl (11) > neopentyl (13). Owing to the fact that the isopropyl group is easily cleavable, the degradation of 9 was observed during storage at room temperature. This highlights that the design of polymers with fast cleavable groups, for processes where sustained thermal treatments are undesired, requires a compromise between lability (for application) and stability (for synthesis and short-term storage) of protecting groups. Hence, the isobutyl group providing both features was investigated further for its thermal processing behaviour and as the switchable component in P3HT-b-PiBSS copolymer.

Aqueous solubility studies of the polymers after isothermal treatment $\left(2 \mathrm{~h}\right.$ at $\left.150^{\circ} \mathrm{C}\right)$ indicated that the branched protected polymers $(\mathbf{9}, \mathbf{1 1}, \mathbf{1 3})$ change from being hydrophobic to hydrophilic following deprotection, as expected, whereas polymers with linear protecting groups $(\mathbf{8}, \mathbf{1 0}, \mathbf{1 2})$ remained hydrophobic. More pertinently, these results have been confirmed by FTIR spectroscopy (Figure S14, ESI). FTIR spectra of poly(isobutyl $p$-styrene sulfonate), 11, before and after deprotection, are shown in Figure 5 as an exemplar.

A huge reduction in intensity of the band associated with alkyl chains $\left[\delta(C-H) \sim 2900 \mathrm{~cm}^{-1}\right]$ and a disappearance of the sharp signal at $1350 \mathrm{~cm}^{-1}$ (related to sulfonate ester) are clearly observed. Simultaneously, a broad band appears in the region of $3500 \mathrm{~cm}^{-1}$, indicative of the presence of the unprotected sulfonate group. It is noteworthy that the data also show a loss of azide functionality $\left(2100 \mathrm{~cm}^{-1}\right)$ in our polymers following thermal treatment, demonstrating the instability of this functional end group in line with the literature. ${ }^{70}$ Consequently, should coupling (via click chemistry ${ }^{64-66}$ ) be required to produce more sophisticated materials, such as block copolymers or hybrid materials, it should be carried out prior to thermal deprotection. As expected from the TGA results, the IR spectra of polymers with linear protecting groups show only minor deprotection. A low-intensity peak in the region of $3500 \mathrm{~cm}^{-1}$ was observed suggesting the presence of a small amount of sulfonic acid groups, however the decrease in intensity of the peaks at $1350 \mathrm{~cm}^{-1}$ and $2900 \mathrm{~cm}^{-1}$ was negligible. This confirms that the removal of the protecting groups was marginal and the majority of protecting groups were not affected by the thermal process.

All of the synthesised polymers have similar dispersity $(1.08<\theta<1.11)$ and all molar masses are in the range of $3000-3900 \mathrm{~g} / \mathrm{mol}$. In order to study the effect of molar mass on deprotection profiles, a series of poly(isobutyl $p$-sulfonate styrenes) with systematically varied $M_{\mathrm{n}}$ was synthesised and probed by TGA. The results presented in Figure 6 show that the overall rate of deprotection $\left(k_{\text {dep }}\right)$ increases together with molar mass of polymer up to $6000 \mathrm{~g} / \mathrm{mol}$ in the following order $k_{\text {dep, } 2400<}$ $k_{\text {dep }, 4600}<k_{\text {dep, } 6000} \approx k_{\text {dep, }} 7000$. It suggests that presented deprotection is an autocatalytic process, in which thermal removal of the first group and generation of a free sulfonic group catalyses cleavage of protecting groups (Figure 7). Similar behaviour was previously reported for acetoacetate derivatives containing (tosyloxy)methyl or (mesyloxy)methyl residues. ${ }^{71}$ The authors proved that the tert-butyl carbonate deprotection initiated by addition of a small amount of $\mathrm{TsOH}$ or $\mathrm{MsOH}$ is subsequently catalysed by $\mathrm{TsOH}$ or $\mathrm{MsOH}$ generated as fragmentation by-products. The 
dependence of the deprotection rate on molar mass shown herein could be related to the differences in mobility between short and long polymer chains. Low molar mass polymers with higher mobility are less susceptible to removal of the protecting group due to their ability to migrate and reduce contact with the highly hydrophilic, isolated sulfonic acid groups, sporadically situated along the polymer backbone, which catalyse the deprotection process. Such migration is driven by the concomitant sudden increase in the Flory-Huggins interaction parameter ([ [iBSS-ss $_{\text {) }}$ ) between the disparate repeat units on the polymer backbone. In contrast, polymers with high molar mass are less mobile and hence less capable of significant migration away from the hydrophilic acidic groups along the backbone. Consequently, a "nuclei" of acidic groups will begin to form, spreading throughout the bulk of the polymer. Clearly, a threshold molar mass is reached whereby a maximum rate of autocatalysed deprotection is reached.

In order to investigate whether free sulfonic acid groups increase the rate of deprotection of the sulfonate ester groups in PiBSS, an additional experiment was performed. Here, mixed samples containing known mass ratios of PiBSS $\left(M_{\mathrm{n}}=3900 \mathrm{~g} / \mathrm{mol}, \Theta=1.16\right)$ and PSS $\left(M_{\mathrm{n}}=75000 \mathrm{~g} / \mathrm{mol}\right)$ homopolymers, were subjected to isothermal thermogravimetric analyses $\left(150^{\circ} \mathrm{C}, 2 \mathrm{~h}\right.$, Figure 8 , Figure S18) TGA thermograms of PiBSS (control) and PiBSS doped with PSS at 11.9, 26.2, 41.1 and $52.2 \%(\mathrm{w} / \mathrm{w})$ are presented in Figure 8. A minor increase in the deprotection rate was observed for the highest loadings of PSS (52.2 and 41.1 \%) PSS-doped PiBSS, whereas the control sample, 11.9 and $26.2 \%$ PSS-doped PiBSS presented similar behaviour. Expected weight loss for PSS-doped PiBSS was calculated assuming that PiBSS weight loss will be at the same level as for the control sample (i.e. $9 \%$ after 50 min of heating). The obtained numbers closely matched the experimental results showing that the addition of PSS has no influence on the extent of isobutyl group removal and side rearrangements. Overall, these results suggest that indeed the presence of PSS, created during the thermolysis of PiBSS, does speed up the deprotection rate and gives credence to our speculations as to the effect of molar mass on the thermolysis profiles. The somewhat meagre effect on the rate of adding free PSS (shown in Figure 8) is attributed to enhanced ability of iBSS groups to migrate away from free PSS in a blend than anchored SS groups located along its backbone.

\section{Synthesis, characterisation and thermal modification of P3HT-b-PiBSS}

To further confirm fidelity of the terminal azide functionality of the PiBSS polymer (PiBSS- $N_{3}, M_{n}=$ $3900 \mathrm{~g} / \mathrm{mol} ; \Xi=1.16$ ) and to fabricate a thermally modifiable material for future use in organic photovoltaic devices, a P3HT ${ }_{50}-b$-PiBSS ${ }_{14}\left(D_{\mathrm{p}}\right.$ was estimated from ${ }^{1} \mathrm{H}$ NMR and GPC, for P3HT and PiBSS, respectively) diblock copolymer was synthesised via click coupling of alkyne-functionalised P3HT (P3HT-ethynyl) and PiBSS-N ${ }_{3}$, according to the method previously reported (Scheme S17, ESI). ${ }^{49}$ Figure 9 shows the GPC traces and FTIR spectra obtained for PiBSS- $\mathrm{N}_{3}$ and P3HT-ethynyl building blocks, along with those obtained for the resultant diblock copolymer, P3HT- $b$-PiBSS $\left({ }^{1} \mathrm{H}\right.$ NMR spectra are provided in the ESI, Figures S20-S22). The GPC traces clearly reveal the expected unimodal increase to higher molar mass of the diblock material $\left(M_{\mathrm{n}}=19500 \mathrm{~g} / \mathrm{mol} ; \emptyset=1.27\right)$; while the FTIR spectrum of P3HT- $b$-PiBSS shows a combination of the individual building blocks, accompanied by the expected absence of azide and alkyne bands $\left(2113 \mathrm{~cm}^{-1}\right.$ in PiBSS- $\mathrm{N}_{3}$ and 2141 $\mathrm{cm}^{-1}$ in P3HT-ethynyl, respectively) (Figure 9).

The thermal modification behaviour of the PiBSS-N $\mathrm{N}_{3}$ homopolymer and corresponding P3HT- $b$-PiBSS diblock copolymer were investigated by isothermal TGA $\left(150^{\circ} \mathrm{C}, 3 \mathrm{~h}\right)$, water contact angle 
measurements and FTIR spectroscopy (before and after thermal treatment) as shown in Figure 10. TGA confirmed complete removal of the isobutyl group (Figure 10a) from P3HT-b-PiBSS (observed $6.5 \%$ weight loss, expected $6.3 \%$ weight loss for complete deprotection). The water contact angle of a film of the diblock copolymer concomitantly changed from $99.4^{\circ}$ to $89.7^{\circ}$ after heating at $150^{\circ} \mathrm{C}$ for $3 \mathrm{~h}$, indicating the expected increase in surface hydrophilicity due to the formation of free sulfonic acid groups in the block copolymer. It is important to note that replacing the neopentyl group in $\mathrm{P}_{3} \mathrm{HT}_{50}-b$ - $\mathrm{PNSS}_{16}$ with the isobutyl protecting group used in the current diblock material $\left(\mathrm{P}_{3} \mathrm{HT}_{50}-\mathrm{b}-\mathrm{PiBSS}_{14}\right)$, resulted in a decrease in the required deprotection time (at $150{ }^{\circ} \mathrm{C}$ ) from $3 \mathrm{~h}$ (for $\left.\mathrm{P}_{3} \mathrm{HT}_{50}-b-\mathrm{PNSS}_{16}\right)^{49}$ to around 45 minutes(for $\mathrm{P}_{3} \mathrm{HT}_{50}-b$ - $\mathrm{PiBSS}_{14}$ ). The reduction of time needed for removal of protecting groups is crucial for industrial application of P3HT- $b$-PiBSS where long thermal treatment at elevated temperature is undesired (e.g. roll-to-roll production of OPV). Consistent with the aforementioned isothermal experiments (Figure 6), the control PiBSS- $\mathrm{N}_{3}$ homopolymer only underwent $49.8 \%$ of the expected mass loss (observed $10.2 \%$ compared to the theoretical $20.5 \%$ ). This is attributed to the Friedel-Crafts rearrangement occurring in PiBSS homopolymer, but not observed in P3HT copolymer. ${ }^{49}$ Nevertheless, the surface hydrophilicity increased significantly as a result of the thermal treatment, giving rise to a water contact angle of $51.4^{\circ}$ compared with a contact angle of $85.9^{\circ}$ measured for PiBSS- $\mathrm{N}_{3}$ prior to thermal treatment. Regardless of the extent of deprotection observed by TGA for thermally treated PiBSS- $\mathrm{N}_{3}$ and P3HT-b-PiBSS, the FTIR spectra of both materials displayed broad bands around $3300 \mathrm{~cm}^{-1}$ which clearly implies free sulfonic acid groups are formed upon thermal treatment (Figure 10b).

\section{Conclusions}

In summary, a series of R-protected $p$-styrene sulfonate monomers have been synthesised and polymerised by RAFT. The conditions applied resulted in high quality polymers characterised by low molar mass dispersities and unimodal GPC traces. Additionally, the use of an azide functionalised chain transfer agent allowed preparation of potential building blocks for click chemistry. Thermolysis of linear alkyl group protected polymers at $150^{\circ} \mathrm{C}$ caused only partial deprotection whereas thermal treatment of branched alkyl group protected products yielded hydrophilic polymer, poly( $p$-styrene sulfonate). Thermal studies of the polymers showed the deprotection rate followed the order (starting with the most readily deprotected): isopropyl > isobutyl > neopentyl; however the spontaneous degradation of the isopropyl-protected polymer was observed during short-term storage. Thus, the isobutyl group proved to be the most thermally labile protecting group that was storage stable at room temperature. The synthesis of P3HT-b-PiBSS from P3HT-ethynyl and PiBSSazide demonstrated the success of azide-alkyne strategy and subsequent thermal studies of the copolymer showed that the deprotection time can be shortened by judicious selection of the PSS protecting group. The conducted studies provide a strategy for the in situ fabrication of amphiphilic polymers, cast from organic solvents, where chemical cleavage of protecting groups is undesirable.

\section{Acknowledgements}

The research leading to these results has received funding from the European Union Seventh Framework Programme (FP7/2011 under grant agreement ESTABLIS $n^{\circ}$ 290022). We thank Professor Yvonne Perrie and Jiteen Ahmed (School of Life \& Health Sciences, Aston University) for their help with TGA measurements.

\section{References}


1. M. M. Saleh, Desalination, 2009, 235, 319-329.

2. A. Rivard, S. Raup and G. Beilman, Journal of Parenteral and Enteral Nutrition, 2004, 28, 7678.

3. J. A. Simoes, D. M. Citron, A. Aroutcheva, R. A. Anderson, C. J. Chany II, D. P. Waller, S. Faro and L. J. D. Zaneveld, Antimicrobial Agents and Chemotherapy, 2002, 46, 2692-2695.

4. J. Girard, P. S. Brunetto, O. Braissant, Z. Rajacic, N. Khanna, R. Landmann, A. U. Daniels and K. M. Fromm, Comptes Rendus Chimie, 2013, 16, 550-556.

5. J. Yu, B. Yi, D. Xing, F. Liu, Z. Shao, Y. Fu and H. Zhang, Physical Chemistry Chemical Physics, 2003, 5, 611-615.

6. Z. Hu, J. Zhang and Y. Zhu, Renewable Energy, 2014, 62, 100-105.

7. L. Groenendaal, F. Jonas, D. Freitag, H. Pielartzik and J. R. Reynolds, Advanced Materials, 2000, 12, 481-494.

8. T. P. Nguyen, P. Le Rendu, P. D. Long and S. A. De Vos, Surface and Coatings Technology, 2004, 180-181, 646-649.

9. Q. Dong, Y. Zhou, J. Pei, Z. Liu, Y. Li, S. Yao, J. Zhang and W. Tian, Organic Electronics, 2010, 11, 1327-1331.

10. T. Higashihara and M. Ueda, Macromol. Res., 2013, 21, 257-271.

11. G. Dennler, M. C. Scharber and C. J. Brabec, Advanced Materials, 2009, 21, 1323-1338.

12. T.-Y. Chu, S. Alem, P. G. Verly, S. Wakim, J. Lu, Y. Tao, S. Beaupré, M. Leclerc, F. Bélanger, D. Désilets, S. Rodman, D. Waller and R. Gaudiana, Applied Physics Letters, 2009, 95, -.

13. P.-L. T. Boudreault, S. Beaupre and M. Leclerc, Polymer Chemistry, 2010, 1, 127-136.

14. J. Roncali, Chemical Society Reviews, 2005, 34, 483-495.

15. E. K. Oikonomou, A. Bethani, G. Bokias and J. K. Kallitsis, European Polymer Journal, 2011, 47, 752-761.

16. C. Zhu, Z. Chen, C. Ni, J. Yu, B. Huang and M. Shan, Polymer-Plastics Technology and Engineering, 2011, 50, 1262-1265.

17. M. Bouix, J. Gouzi, B. Charleux, J.-P. Vairon and P. Guinot, Macromolecular Rapid Communications, 1998, 19, 209-213.

18. J. E. Coughlin, A. Reisch, M. Z. Markarian and J. B. Schlenoff, Journal of Polymer Science Part A: Polymer Chemistry, 2013, 51, 2416-2424.

19. N. Shibuya and R. S. Porter, Macromolecules, 1992, 25, 6495-6499.

20. F. P. Regas, Polymer, 1984, 25, 249-253. 
21. F. Kučera and J. Jančář, Polymer Engineering \& Science, 1998, 38, 783-792.

22. D. W. Brown and R. E. Lowry, Journal of Polymer Science: Polymer Chemistry Edition, 1979, $17,1039-1046$.

23. F. Kucera and J. Jancar, Polymer Engineering \& Science, 2009, 49, 1839-1845.

24. B. Keoshkerian, M. K. Georges and D. Boils-Boissier, Macromolecules, 1995, 28, 6381-6382.

25. L. I. Gabaston, S. A. Furlong, R. A. Jackson and S. P. Armes, Polymer, 1999, 40, 4505-4514.

26. X. S. Wang, R. A. Jackson and S. P. Armes, Macromolecules, 1999, 33, 255-257.

27. C.-K. Choi and Y.-B. Kim, Polymer Bulletin, 2003, 49, 433-439.

28. P. D. Iddon, K. L. Robinson and S. P. Armes, Polymer, 2004, 45, 759-768.

29. J. Chiefari, Y. K. Chong, F. Ercole, J. Krstina, J. Jeffery, T. P. T. Le, R. T. A. Mayadunne, G. F. Meijs, C. L. Moad, G. Moad, E. Rizzardo and S. H. Thang, Macromolecules, 1998, 31, 5559-5562.

30. Y. Mitsukami, M. S. Donovan, A. B. Lowe and C. L. McCormick, Macromolecules, 2001, 34, 2248-2256.

31. B. S. Sumerlin, A. B. Lowe, P. A. Stroud, P. Zhang, M. W. Urban and C. L. McCormick, Langmuir, 2003, 19, 5559-5562.

32. F. D. Sikkema, M. Comellas-Aragones, R. G. Fokkink, B. J. M. Verduin, J. J. L. M. Cornelissen and R. J. M. Nolte, Organic \& Biomolecular Chemistry, 2007, 5, 54-57.

33. K. Lienkamp, I. Schnell, F. Groehn and G. Wegner, Macromolecular Chemistry and Physics, 2006, 207, 2066-2073.

34. K.-Y. Baek, Journal of Polymer Science Part A: Polymer Chemistry, 2008, 46, 5991-5998.

35. K.-Y. Baek, Molecular Crystals and Liquid Crystals, 2010, 520, 256/[532]-261/[537].

36. K.-Y. Baek, H.-J. Kim, S.-H. Lee, K.-Y. Cho, H. T. Kim and S. S. Hwang, Macromolecular Chemistry and Physics, 2010, 211, 613-617.

37. X. Li, Y. Jiang, L. Shuai, L. Wang, L. Meng and X. Mu, Journal of Materials Chemistry, 2012, 22, 1283-1289.

38. H. Zhong, Z. Li, E. Buchaca-Domingo, S. Rossbauer, S. E. Watkins, N. Stingelin, T. D. Anthopoulos and M. Heeney, Journal of Materials Chemistry A, 2013, 1, 14973-14981.

39. K. W. Song, H. J. Song, T. H. Lee, S. W. Heo and D. K. Moon, Polymer Chemistry, 2013, 4, 3225-3235.

40. M. Manceau, A. Rivaton, J.-L. Gardette, S. Guillerez and N. Lemaître, Polymer Degradation and Stability, 2009, 94, 898-907. 
41. M. Manceau, E. Bundgaard, J. E. Carle, O. Hagemann, M. Helgesen, R. Sondergaard, M. Jorgensen and F. C. Krebs, Journal of Materials Chemistry, 2011, 21, 4132-4141.

42. B. D. Reeves, E. Unur, N. Ananthakrishnan and J. R. Reynolds, Macromolecules, 2007, 40, 5344-5352.

43. X. Han, X. Chen and S. Holdcroft, Advanced Materials, 2007, 19, 1697-1702.

44. S. A. Gevorgyan and F. C. Krebs, Chemistry of Materials, 2008, 20, 4386-4390.

45. C. Edder, P. B. Armstrong, K. B. Prado and J. M. J. Frechet, Chemical Communications, 2006, DOI: 10.1039/B601296P, 1965-1967.

46. M. Helgesen and F. C. Krebs, Macromolecules, 2010, 43, 1253-1260.

47. M.-C. Choi, Y. Kim and C.-S. Ha, Progress in Polymer Science, 2008, 33, 581-630.

48. R. R. Søndergaard, K. Norrman and F. C. Krebs, Journal of Polymer Science Part A: Polymer Chemistry, 2012, 50, 1127-1132.

49. H. Erothu, J. Kolomanska, P. Johnston, S. Schumann, D. Deribew, D. T. W. Toolan, A. Gregori, C. Dagron-Lartigau, G. Portale, W. Bras, T. Arnold, A. Distler, R. C. Hiorns, P. Mokarian-Tabari, T. W. Collins, J. R. Howse and P. D. Topham, Macromolecules, 2015, 48, 2107-2117.

50. P. Gricaj, Zhurnal Organicheskoi Khimii, 1967, 3, 1597-1598.

51. I. H. Spinner, J. Ciric and W. F. Graydon, Canadian Journal of Chemistry, 1954, 32, 143-152.

52. M. Shirai, J. Nakanishi, M. Tsunooka, T. Matsuo and M. Endo, Journal of Photopolymer Science and Technology, 1998, 11, 641-644.

53. H. Okamura, Y. Takatori, M. Tsunooka and M. Shirai, Polymer, 2002, 43, 3155-3162.

54. G. Moad, E. Rizzardo and S. H. Thang, Australian Journal of Chemistry, 2005, 58, 379-410.

55. M. Semsarilar and S. Perrier, Nat Chem, 2010, 2, 811-820.

56. D. J. Keddie, Chemical Society Reviews, 2014, 43, 496-505.

57. K. Matsumoto, T. Hirabayashi, T. Harada and H. Matsuoka, Macromolecules, 2005, 38, 99579962.

58. K. Matsumoto, S. Kage and H. Matsuoka, Journal of Polymer Science Part A: Polymer Chemistry, 2007, 45, 1316-1323.

59. K. Matsumoto, F. Ozaki and H. Matsuoka, Journal of Polymer Science Part A: Polymer Chemistry, 2008, 46, 4479-4485.

60. J. C. Brendel, H. Burchardt and M. Thelakkat, Journal of Materials Chemistry, 2012, 22, 24386-24393.

61. A. Vora, K. Singh and D. C. Webster, Polymer, 2009, 50, 2768-2774. 
62. K. Schuh, O. Prucker and J. r. Rühe, Macromolecules, 2008, 41, 9284-9289.

63. I. Fraga Domínguez, J. Kolomanska, P. Johnston, A. Rivaton and P. D. Topham, Polymer International, 2015, 64, 621-630.

64. W. H. Binder and R. Sachsenhofer, Macromolecular Rapid Communications, 2007, 28, 15-54.

65. A. P. Vogt and B. S. Sumerlin, Macromolecules, 2006, 39, 5286-5292.

66. W. Agut, D. Taton and S. Lecommandoux, Macromolecules, 2007, 40, 5653-5661.

67. V. Ladmiral, T. M. Legge, Y. Zhao and S. Perrier, Macromolecules, 2008, 41, 6728-6732.

68. K. S. Khuong, W. H. Jones, W. A. Pryor and K. N. Houk, Journal of the American Chemical Society, 2005, 127, 1265-1277.

69. C. J. Ruud, J. Jia and G. L. Baker, Macromolecules, 2000, 33, 8184-8191.

70. S. Bräse, C. Gil, K. Knepper and V. Zimmermann, Angewandte Chemie International Edition, $2005,44,5188-5240$.

71. K. Arimitsu, K. Kudo and K. Ichimura, Journal of the American Chemical Society, 1998, 120, 37-45.

\section{Figures/Tables/Schemes}

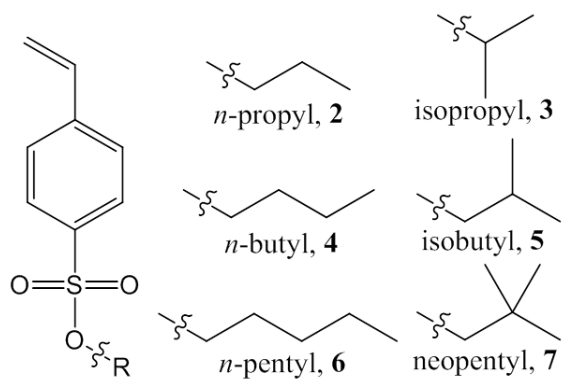




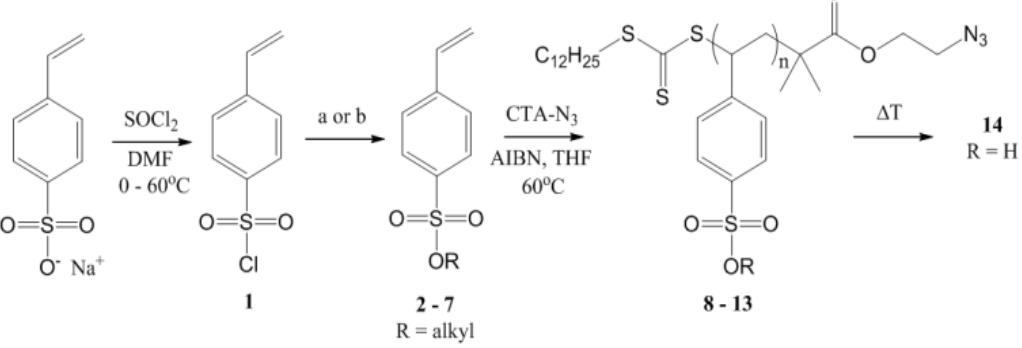

Scheme 1 Reaction scheme for poly( $p$-styrene sulfonate) via the synthesis of alkyl protected monomers [conditions were (a) neopentyl alcohol, pyridine, 0 ${ }^{\circ} \mathrm{C}-\mathrm{RT}$ for 7 and (b) ROH, DABCO, DCM, $0{ }^{\circ} \mathrm{C}-\mathrm{RT}$ for 2-6], RAFT polymerisation and subsequent thermolysis.
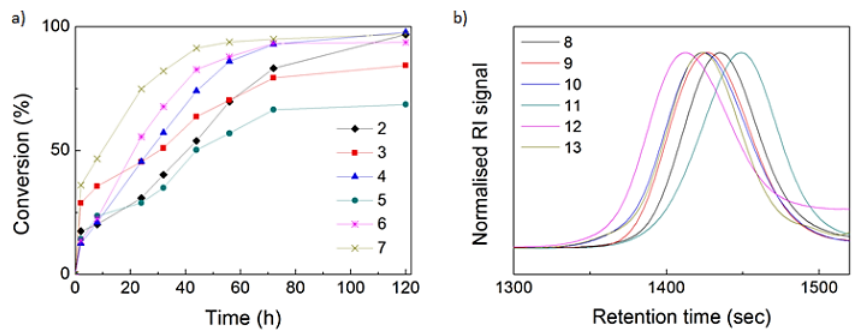

Fig. 2 (a) Monomer conversion during the RAFT polymerisation of R-protected $p$ styrene sulfonate monomers (2-7) to yield polymers (8-13), (b) GPC traces of Rprotected $p$-styrene sulfonate polymers (8-13).

Table 1 RAFT polymerisation of alkyl-protected styrene sulfonate monomers 2-7.

\begin{tabular}{|c|c|c|c|c|c|c|c|}
\hline Product & $\mathrm{R}$ & $\begin{array}{l}M_{\mathrm{n}}^{\text {th a }} \\
\mathrm{g} \mathrm{mol}^{-1}\end{array}$ & $\begin{array}{c}\text { Time } \\
\mathrm{h}\end{array}$ & $\begin{array}{c}\text { Monomer } \\
\text { conversion }^{\mathrm{b}} \\
\% \\
\end{array}$ & $M_{\mathrm{n}}{ }^{\mathrm{c}}$ & $\begin{array}{c}\bigoplus \\
\left(M_{\mathrm{w}} / M_{\mathrm{n}}\right)^{\mathrm{c}}\end{array}$ & $\begin{array}{c}k_{\mathrm{app}}{ }^{\mathrm{d}} \\
\mathrm{h}^{-1}\end{array}$ \\
\hline 9 & isopropyl (3) & 5590 & 72 & 92 & 3800 & 1.08 & 0.019 \\
\hline 10 & n-butyl (4) & 5150 & 120 & 98 & 3800 & 1.08 & $0.025\left(k_{1}\right) ; 0.045\left(k_{2}\right)$ \\
\hline 11 & isobutyl (5) & 5150 & 120 & 69 & 3000 & 1.08 & 0.014 \\
\hline 12 & n-pentyl (6) & 5430 & 120 & 94 & 3900 & 1.08 & 0.038 \\
\hline 13 & neopentyl (7) & 5430 & 120 & 97 & 3500 & 1.11 & $0.051\left(k_{1}\right) ; 0.019\left(k_{2}\right)^{6}$ \\
\hline
\end{tabular}

(a) Target degree of polymerisation, $D_{\mathrm{p}}=20$, with the exception of product 9 (target $D_{\mathrm{p}}=25$ ), which required a higher final target to achieve a similar $M_{\mathrm{n}}$ to the others in the study because prolonged polymerisation times ( $>72 \mathrm{~h}$ ) induced thermal deprotection of the polymer; (b) Determined by ${ }^{1} \mathrm{H}$ NMR spectroscopy; (c) Determined by THF GPC (PS standards); (d) calculated for 0-72 h (Figure S16, ESI); (e) $k_{1}$ for 0-44h, $\mathrm{k}_{2}$ for 44-72 h; (f) $k_{1}$ for 0-32h, $k_{2}$ for 32-72 h. 


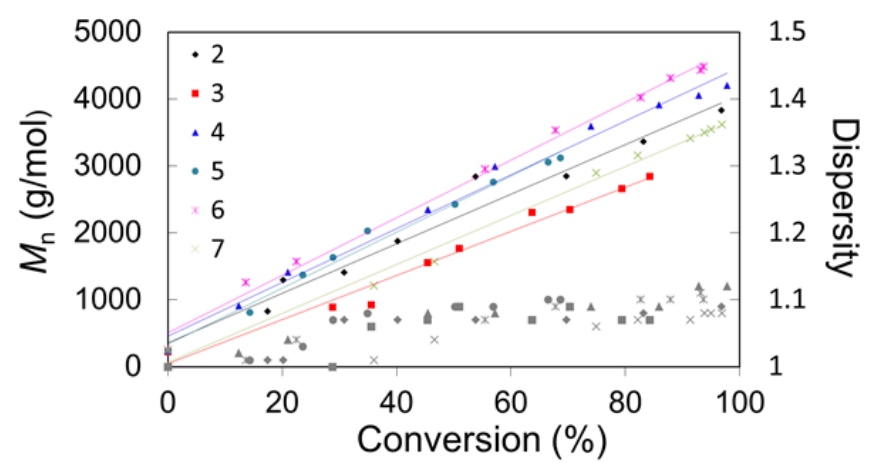

Fig. 3 Plot of molar mass and dispersity versus conversion for the polymerisation of monomers 2-7.
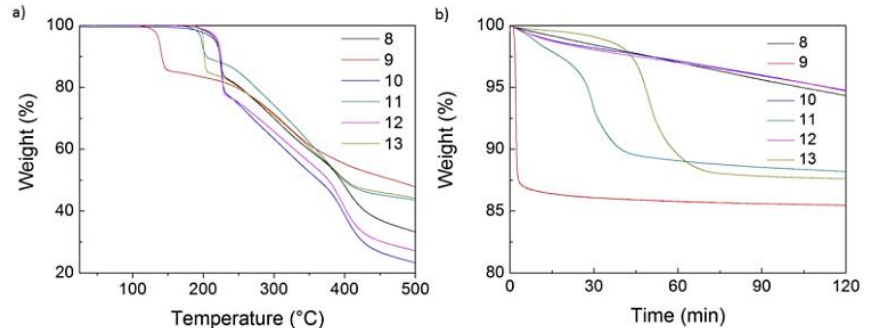

Fig. 4 TGA thermograms of polymers $\mathbf{8 - 1 3}$ for (a) a thermal sweep at a rate of $10^{\circ} \mathrm{C} / \mathrm{min}$ and $(\mathrm{b})$ isothermal degradation at $150^{\circ} \mathrm{C}$.

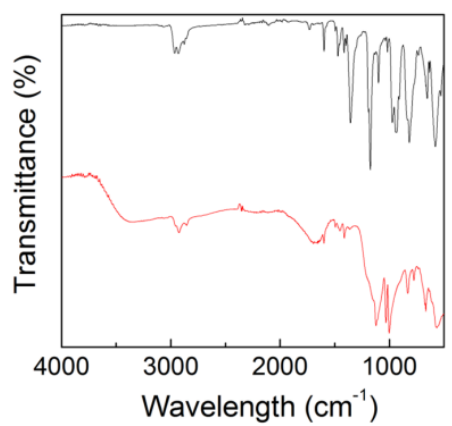

Fig. 5 FTIR traces of poly( $p$-isobutyl styrene sulfonate) before (upper) and after deprotection (lower). 


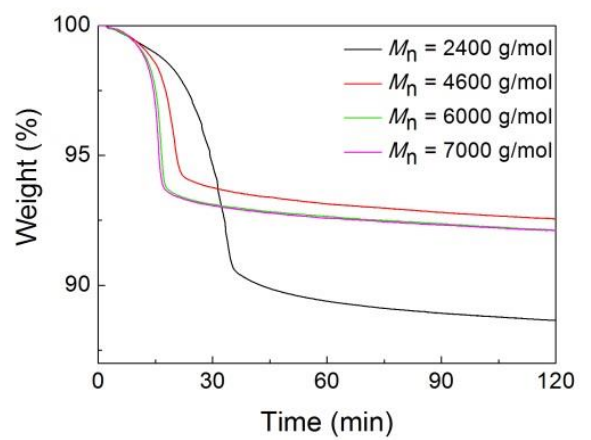

Fig. 6 TGA thermograms of poly(isobutyl $p$-styrene sulfonate) (at different molar masses) under isothermal degradation at $150^{\circ} \mathrm{C}$.

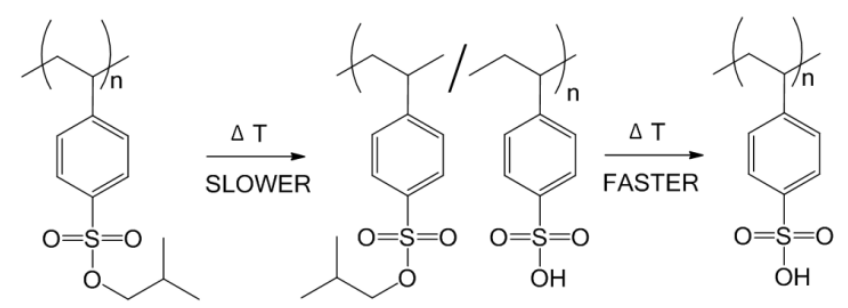

Fig. 7 Autocatalytic removal of isobutyl group.

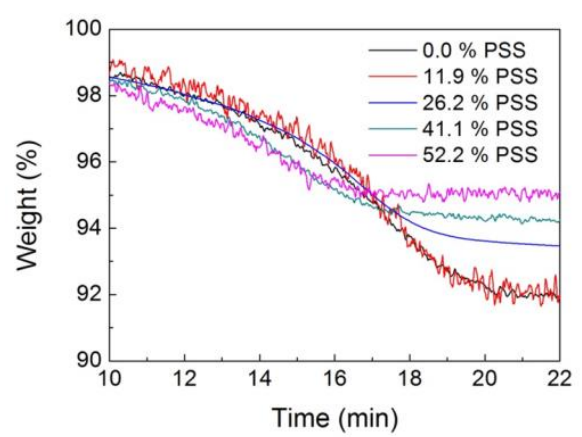

Fig. 8 TGA thermograms of PSS-doped PiBSS for isothermal deprotection at $150^{\circ} \mathrm{C}$. 

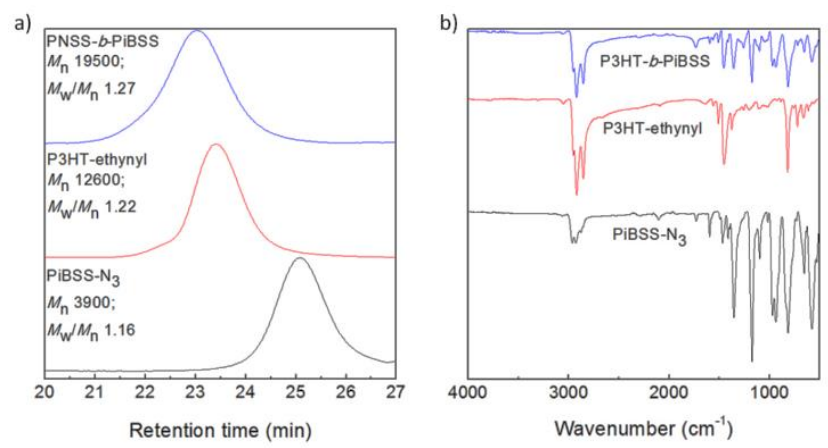

Fig. 9 (a) GPC traces and (b) FTIR spectra of $\mathrm{P}_{3} \mathrm{HT}_{50}-\mathrm{b}-\mathrm{PiBSS}_{14}$, $\mathrm{P}_{3} \mathrm{HT}_{50}$-ethynyl and $\mathrm{PiBSS}_{14}-\mathrm{N}_{3}$.
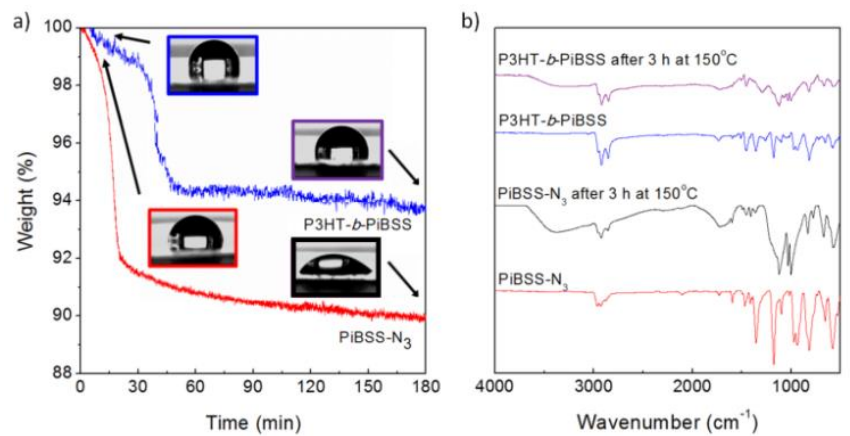

Fig. 10 (a) Isothermal TGA profiles for $\mathrm{P}_{3} \mathrm{HT}_{50}-b-\mathrm{PiBSS}_{14}$ and $\mathrm{PiBSS}_{14}-\mathrm{N}_{3}\left(150{ }^{\circ} \mathrm{C}, 3 \mathrm{~h}\right)$; insets show water contact angles for $\mathrm{P}_{3} \mathrm{HT}_{50}-b-\mathrm{PiBSS}_{14}$ and $\mathrm{PiBSS}_{14}-\mathrm{N}_{3}$ before and after thermal treatment $\left(150^{\circ} \mathrm{C}, 3 \mathrm{~h}\right)$. Contact angles for $\mathrm{P}_{3} \mathrm{HT}_{50}-b$ - $\mathrm{PiBSS}_{14}$ are: $\vartheta$ $=99.4 \pm 2.2^{\circ}$ and $\vartheta_{150^{\circ} \mathrm{C}}=89.7 \pm 3.9^{\circ}$; contact angles for $\mathrm{PiBSS}_{14}-\mathrm{N}_{3}$ are: $\vartheta=85.9 \pm 2.0^{\circ}$ and $\vartheta_{150^{\circ} \mathrm{C}}=51.4^{\circ}$. (b) FTIR spectra of P3HT $50^{-} b$ PiBSS $_{14}$ and PiBSS $_{14}-\mathrm{N}_{3}$ before and after thermal treatment (150 